\title{
Reorientasi Pendidikan Pancasila dan Kewarganegaraan pada sekolah dasar dalam wacana kewarganegaraan smart and good citizen
}

\author{
Yayuk Hidayah, ${ }^{1 *}$, Lisa Retnasari, ${ }^{2}$ \\ ${ }^{a}$ PGSD Universitas Ahmad Dahlan, Yogyakarta \\ ${ }^{\mathrm{b}}$ PGSD Universitas Ahmad Dahlan, Yogyakarta \\ ${ }^{1}$ yayuk.hidayah@pgsd.uad.ac.id ; ${ }^{2}$ lisa.retnasari@pgsd.uad.ac.id \\ ${ }^{*}$ Korespondensi penulis
}

\begin{abstract}
ABSTRAK
Tujuan dari penulisan artikel ini adalah untuk reorientasi Pendidikan Pancasila dan Kewarganegaraan pada Sekolah Dasar dalam wacana kewarganegaraan smart and good citizen, mengkaji mengenai wacana kewarganegaraan. Metode yang digunakan dalam artikel ini adalah library research. Tekhnik pengumpulan data di lakukan dengan coding data. Analisis data yang dilakukan dalam penelitian ini adalah secara induktif, yaitu dengan dua tahapan berupa reduksi data dan penyajian datadokumen. Hasil analisis menunjukan bahwa reorientasi Pendidikan Pancasila dan Kewarganegaraan pada Sekolah Dasar dalam wacana kewarganegaraan merupakan penegasan bahwa Pendidikan Pancasila dan Kewarganegaraan merupakan bagian dari pendidikan karakter. Melalui artikel ini peneliti merekomendasikan peneliti selanjutnya agar melakukan kajian yang meluas dan mendalam mengenai Pendidikan Pancasila dan Kewarganegaraan di Sekolah Dasar
\end{abstract}

Kata kunci: Pancasila dan Kewarganegaraan, Sekolah dasar, Good Citizen

\begin{abstract}
The purpose of this article is to reorient Pancasila and Citizenship Education in Elementary (PPKn) Schools in smart and good citizen citizenship discourse, examining the discourse of citizenship. The method used in this article is library research. Data collection techniques are done by coding data. The data analysis carried out in this study is inductively, with two stages in the form of data reduction and document presentation. The results of the analysis show that the reorientation of Pancasila and Citizenship Education in Primary Schools in the discourse of citizenship is an affirmation that Pancasila and Citizenship Education is part of character education. Through this article the researcher recommends further researchers to conduct a broad and in-depth study of Pancasila and Citizenship Education in Primary Schools (PPKn).
\end{abstract}

Keywords: Pancasila and Citizenship, Primary School, Good Citizen

Copyright @2018Universitas Ahmad Dahlan, All Right Reserved

\section{PENDAHULUAN}

Fungsi dari pendidikan nasional yakni mengembangkan kemampuan dan membentuk watak serta peradaban bangsa yang bermartabat dalam rangka mencerdaskan kehidupan bangsa, bertujuan untuk berkembangnya potensi peserta didik agar menjadi manusia yang beriman dan bertakwa kepada Tuhan Yang Maha Esa, berakhlak mulia, sehat, berilmu, cakap, kreatif, mandiri, dan menjadi warga negara yang demokratis serta bertanggung jawab sebagaimana pasal 3 UU No 20 Tahun 2003.

PKn memiliki misi mengembangkan pendidikan demokrasi secara sosio-pedagogis dan sosio-andragogis yang mampu menjadikan warga negara yang cerdas (Winataputra, 2016). Secara implisit misi tersebut ada tiga yakni civic intellegence, civic responsibility, dan civic particiption. Kecerdasakan yang dikembangkan di dalam PPKn tidak hanya rasional, namun jufa kecerdasan spritual, emosional dan sosial. Selain itu Branson (1999) menekankan dalam era globalisasi PKn harus mampu mengambangkan kompetensi kewarganegaraan (civic competences).

Kompetensi kewarganegaraan meliputi aspek pengetahuan kewarganegaraan (civic knowledge), keterampilan kewarganegaraan (civic skill), dan karakter kewarganegaraan (civic disposition) yang nantinya bermuara membangun karakter warga negara yang baik. Bangsa Indonesia saat ini sedang bergerak menuju ke arah pendewasaan. Harapnya memiliki warga negara yang demokratis seutuhnya, memiliki nilai karakter religius, beradab, bersatu, dan berkeadilan sosial sesuia tujuan dalam dasar negara yakni Pancasila dan UUD 1945.

Pembangunan masyarakat yang memiliki karakter baik tidaklah mudah, harus konsisten dan komitmen secara berkesinambungan. Mulai dari sekolah dasar sebagai pondasi peserta didik untuk 
mampu hidup demokratis di segala lini kehidupan. PPKn sebagai salah satu muatan kurikulum di sekolah dasar, sekolah menengah pertama, sekolah menengah atas dan pertguruan tinggi bermuara dan berlandaskan kepada UUD 1945 dan Pancasila.Kajian ini mencoba untuk melakukan pengenalan mengenai Pendidikan Pancasila Dan Kewarganegaraan pada Sekolah Dasar dalam wacana kewarganegaraan smart and good citizen.

Beberapa penelitian menghasilkan bahwa perkembangan pendidikan moral, sosial dan kewarganegaraan dalam lima Sekolah dasar Yunani, menunjukkan bahwa kurikulum yang diajarkan tentang pendidikan moral, sosial dan kewarganegaraan dan etos adalah saling terkait (Pasoula, 2001). Sementara di Iran, pendekatan pendidikan kewarganegaraan progresif dalam kurikulum sekolah dasar Iran dimensi kognitif pendidikan diberi prioritas di atas dimensi lain. Temuan ini mengungkapkan komponen pendidikan kewarganegaraan progresif diabaikan sebagian besar oleh kurikulum (Gholtash \& Yarmohammadian, 2011).

Pendidikan kewarganegaraan secara formal di AS berada dalam mata pelajaran sejarah dan biasanya di kelas 5, 8, dan 11 (Nuci et al., 2014). Pendidikan kewarganegaraan di sekolah-sekolah Amerika dari tingkat kelas dasar hingga menengah terdiri dari praktik pengajaran khusus yang dirancang untuk mendorong siswa untuk menjadi lebih terlibat dalam komunitas mereka (Lin, 2015). Dalam Pendidikan Kewarganegaraan di Inggris, Norma kewarganegaraan yang diterapkan dalam berbagai domain sosial yang berbeda hal ini untuk memperjelas perjuangan politik yang melekat dan untuk membingkai warga negara yang baik tanpa perbedaan (Pykett et al., 2010).

Di Indonesia, Pendidikan kewarganegaraan di sekolah dasar sebagai kendaraan utama dan memiliki esensi dari pendidikan yang demokratis untuk mencapai kompetensi dalam aspek kewarganegaraan, tanggung jawab sipil, dan partisipasi sipil. Kompetensi inti dalam pendidikan kewarganegaraan di sekolah dasar kompetensi psikologis-pedagogis untuk mengintegrasikan secara penuh dan koheren dengan penanaman, pengembangan, dan penguatan nilai-nilai moral Pancasila; nilai-nilai dan norma Konstitusi Republik Indonesia 1945; nilai-nilai dan semangat persatuan dalam keanekaragaman; serta wawasan dan komitmen Republik Indonesia (Harmanto et al., 2018). Ada tiga cara utama pendidikan kewarganegaraan diintegrasikan ke dalam kurikulum nasional di Eropa, yaitu 1) lintaskurikuler: tujuan pendidikan kewarganegaraan, konten atau hasil pembelajaran ditunjuk sebagai transversal di seluruh kurikulum dan semua guru berbagi tanggung jawab. 2) Diintegrasikan ke dalam mata pelajaran lain: tujuan pendidikan kewarganegaraan, konten atau hasil pembelajaran termasuk dalam kurikulum mata pelajaran yang lebih luas atau bidang pembelajaran, sering berkaitan dengan humaniora / ilmu sosial (De Coster \& Sigalas, 2017). Mata pelajaran atau bidang pembelajaran yang lebih luas ini tidak harus mengandung akomponen berbeda yang didedikasikan untuk pendidikan kewarganegaraan. 3) Subjek terpisah: tujuan pendidikan kewarganegaraan, konten atau hasil pembelajaran terkandung dalam batas subjek yang berbeda terutama didedikasikan untuk kewarganegaraan (De Coster \& Sigalas, 2017).

Berdasarkan uraian tersebut dan sebagaimana amanah dari pasal 37 ayat (1) dan (2) UU No. 20 Tahun 2003 tentang Sistem Pendidikan Nasional bahwa Pendidikan Kewargaegaraan wajib dimuat dalam Pendidikan Dasar hingga Pendidikan Tinggi, maka penulis tertarik untuk melakukan kajian ini dengan tujuan 1) Reorientasi Pendidikan Pancasila Dan Kewarganegaraan pada Sekolah Dasar dalam wacana kewarganegaraan smart and good citizen. 2) mengkaji mengenai wacana kewarganegaraan.

\section{METODE}

Metode yang digunakan dalam penelitian ini adalah dengan menggunakan library research. Penelitian library research yaitu pengumpulan data berupa pustakaan (Mahmud, 2011). Prosedur penelitian di mulai dengan pengumpulan data yaitu mengidentiifkasi refrensi yang berkaitan denga tema. Tekhnik pengumpulan data di lakukan dengan coding data. Analisis data yang di lakukan dalam penelitian ini adalah secara induktif, yaitu dengan dua ahapan berupa reduksi data dan penyajian datadokumen,catatan,majalah dan kisah dalam sejarah (Sholeh, 2005). Subjek penelitian adalah literatur mengenai Pendidikan Pancasila dan Kewarganegaraan, Pendidikan Pancasila dan Kewarganegaraan Sekolah dasar, Good citizen.

\section{HASIL DAN PEMBAHASAN}

Pada bagian hasil dan pembahasan, peneliti mencoba mengemukakan hasil kajian dengan memadukan secara langsung dengan pembahasan. Peneliti berupaya menyajikan dalam pembahasan dengan cakupan "what?"

\section{Reorientasi Pendidikan Pancasila Dan Kewarganegaraan pada Sekolah Dasar dalam wacana kewarganegaraan smart and good citizen.}

Wacana kewarganegaraan smart and good citizen menjadi keberlanjutan dari ramainya pembicaraan mengenai pendidikan karakter di dunia pendidikan Indonesia. Dalam sejarah banga 
Indonesia, Pendidika karakter telah lama ada. Tercatat terdapat dalam Pembukaan UUD 1954 alenia ke 2(Afandi, 2011). Reorientasi pendidikan pancasila dan kewarganegaraan pada sekolah dasar dalam wacana kewarganegaraan menjadi urgent ketika berpijak pada amanah dari pasal 37 ayat (1) dan (2) UU No. 20 Tahun 2003 tentang Sistem Pendidikan Nasional.

Terdapat beberapa alasan mengenai pentingnya reorientasi Pendidikan Pancasila Dan Kewarganegaraan pada Sekolah Dasar dalam wacana kewarganegaraan, pertama, usia Sekolah Dasar merupakan kesempatan yang dapat dimanfaatkan untuk menanamkan konsep kepada anak. Usia SD yaitu, antara 7-12 tahun menurut piaget merupakan berada pada tahapan operasional konkrit, yaitu menggunakan logika yang memadai (Hardianto, 2014) . Kedua, jenjang Sekolah Dasar merupakan masa pengalihan dari lingkungan yang sebelumnya (keluarga) ke masa anak-anak bertemu dengan lingkungan yang lebih luas. Saat seperti ini adalah masa ketika perubahan perkembangan terjadi yang dapat terjadi. Penyebab permasalahan perkembangan anak terdapat beberapa faktor, yaitu perkembangan emosional, sosial, kognitif, intelketual, bahasa, fisik (Izzaty, 2008). Seiring dengan melejitnya pendidikan karakter yang telah lama ramai di jagad Pendidikan Indonesia sejak 2010. Pendidikan karakter telah di canangkan Pemerintah melalui Kemendikbud sejak 2010 (Adawiah, 2016). Dalam hal hakikat konten, Pendidikan karakter sudah ada sejak beririringan dengan sejarah pendidikan itu sendiri (Sudrajat, 2011). Wacana kewarganegaraan smart and good citizen tertuju pada konsep karakter yang baik. Sementara itu, karakter yang baik merupakan konstruksi dari berbagai aspek yang saling berkaitan. Karakter yang baik berkaitan dengan mengetahui yang baik (knowing the good), mencintai yang baik (loving the good), dan melakukan yang baik (acting the good) (Sudrajat, 2011).

Jika di hubungkan dengan Pendidikan karakter, Peran Pendidikan Kewarganegaraan dalam mewujudkan karakter warga negara yang sesuai dengan karakter bangsa (Ananda, 2012). Pendidikan Kewarganegaraan telah menjadi konsep integratif dari tujuan pendidikan yang yang menyatu dalam pendidikan berpusat pada peserta didik (Pineda-Alfonso, 2016). Pendidikan karakter pada sekolah dasar menjadi salah satu keberlangsungan pendidikan ke tahap selanjutnya (Hidayah et al., 2018). Berikut adalah hasil penelitian sistematika Pendidikan Kewarganegaraan di berbagai negara

Tabel 1. Sistematika Pendidikan Kewarganegaraan di berbagai negara

\begin{tabular}{|c|c|c|c|}
\hline Country & Terminology & Approach & Hour per week \\
\hline England & Education for Citizenship & Non-statutory, cross curricular & Schools to decide \\
\hline Canada & Social studies & Non-statutory, Integrated & Not specified \\
\hline France & $\begin{array}{l}\text { Civics as part of } \\
\text { "Discovering the World" }\end{array}$ & $\begin{array}{l}\text { Statutory core Separate and } \\
\text { Integrated }\end{array}$ & 4 hours out of 26 \\
\hline Germany & Sachunterricht & Non-statutory, Integrated & Not specified \\
\hline Hungary & People and society & Statutory core Integrated & $\begin{array}{l}4 \text { to } 7 \% \text { of curriculum } \\
\text { time }\end{array}$ \\
\hline Italy & Social sciences & Statutory core Integrated & Not specified \\
\hline The Netherland & Social structure and life skills & Statutory core Integrated & 80 to 100 hours per year \\
\hline Spain & $\begin{array}{l}\text { Knowledge of natural, social, } \\
\text { and cultural environment }\end{array}$ & Non-statutory, Integrated & 170 hours per year \\
\hline Sweden & Social sciences & Noncore Integrated & $\begin{array}{l}885 \text { hours over } 9 \text { years of } \\
\text { compulsory education }\end{array}$ \\
\hline Switzerland & Social sciences & Non statutory Integrated & Not specified \\
\hline USA: Kentucky & Social sciences & Statutory core Integrated & $\begin{array}{l}\text { Time specified per week } \\
\text { varies a }\end{array}$ \\
\hline Indonesia[5] & $\begin{array}{l}\text { Pancasila and Civic } \\
\text { Education }\end{array}$ & Integrated & $\begin{array}{l}\text { Average } 70 \text { minute per } \\
\text { week }\end{array}$ \\
\hline
\end{tabular}

Sumber: (Harmanto, Listyaningsih, 2018)

Dengan diberlakukannya kurikulum 2013, kajian Pendidikan Pancasila dan Kewarganegaraan untuk tingkat sekolah dasar juga ada terdapat penyesuaian. Berikut adalah muatan Pendidikan Pancasila dan Kewarganegaraan dalam kurikulum 2013 untuk jenjang sekolah dasar. 
Yayuk Hidayah, dkk. Reorientasi Pendidikan Pancasila dan Kewarganegaraan pada sekolah dasar dalam wacana kewarganegaraan smart and good citizen

Tabel 2 Muatan Pendidikan Pancasila dan Kewarganegaraan dalam Kurikulum 2013 untuk Jenjang Sekolah Dasar

\begin{tabular}{|l|}
\hline Kurikulum $2013 \rightarrow$ Pendidikan Pancasila dan Kewarganegaraan \\
\hline \multicolumn{1}{|c|}{ Kajian PPKn pada Kurikulum 2013 jenjang SD/MI } \\
\hline Keberagaman, Kerukunan, Gotong royong \\
\hline Undang-undang Dasar 1945 \\
\hline Lambang Negara:Garuda Pancasila \\
\hline Nilai-nilai dan moral yang terkandung didalam pancasila \\
\hline $\begin{array}{l}\text { Menaati hukum dan peraturan perundang-undangan dalam sistem hukum di } \\
\text { Indonesia }\end{array}$ \\
\hline Kebersamaan dalam keberagaman atau Bhinneka Tunggal Ika \\
\hline Hak, kewajiban dan tanggung jawab warga negara \\
\hline Persatuan dan kesatuan bangsa \\
\hline Cinta tanah air (patriotisme) \\
\hline Hak Asasi Manusia \\
\hline Negara Kesatuan Republik Indonesia (NKRI) \\
\hline
\end{tabular}

Sumber: (Galih Puji Mulyoto, Nur Hidayah Hanifah, 2018)

\section{Smart and Good Citizen}

Aristoteles telah membedakan good citizen dan good man, konstitusi membutuhkan tipe warga negara yang berbeda (Heater, 2002). Warga negara yang baik merupakan kombinasi dari berbagai aspirasi dari kekuatan politik dalam masyarakat
(Suyato et al., 2016). Dalam wacana kewarganegaraan yaitu smart and god citizen merupakan titik temu antara civic confidence, civic competence dan civic commitment (Winarno, 2012) ke tiga skema tersebut, Winarno menggambaran sebagai berikut:

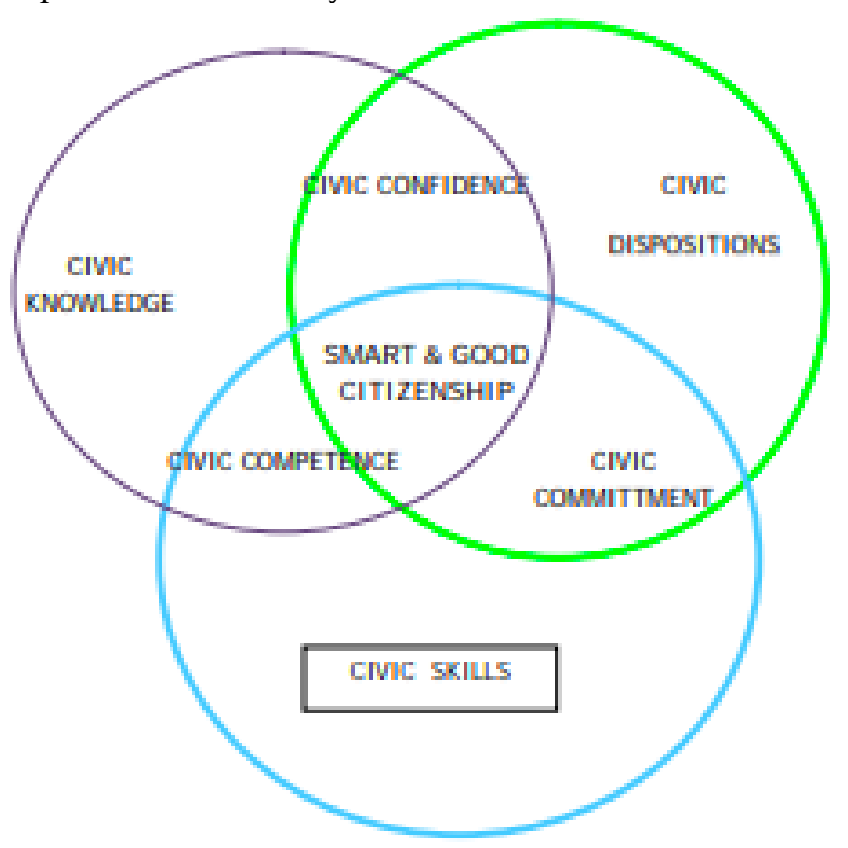

Gambar 1. Dimensi Kewarganegaraan

Sumber: (Winarno, 2012)

Wacana kewarganegaraan smart and god citizen merujuk pada beberapa term yaitu cerdas, karakter dan baik. Pendidikan karakter menjadi perhatian sejak Thomas Lickona pada tahun 1990- an dalam bukunya How Our School Can Teach Respect and Responsibility menggagasa pentingnya pendidikan karakter. Menumbuhkan karakter yang baik di antara anak-anak dan remaja telah lama 
menjadi tujuan orang tua pendidik, dan teolog di mana-mana (Proctor, 2016) Dalam lingkungan pendidikan, pendidikan Karakter telah dilakukan baik secara formal maupun secara informal. Ini dimaksudkan sebagai salah satu pendukung untuk tindak lanjut dalam bentuk desain kegiatan (Kamaruddin, 2012). Karakter moral dapat dikonseptualisasikan sebagai kecenderungan individu untuk berpikir, merasakan, dan berperilaku secara etis versus tidak etis, atau sebagai bagian dari perbedaan individu yang relevan dengan moralitas (Cohen et al., 2014). Sebagai upaya pembentuan karakter untuk dapat

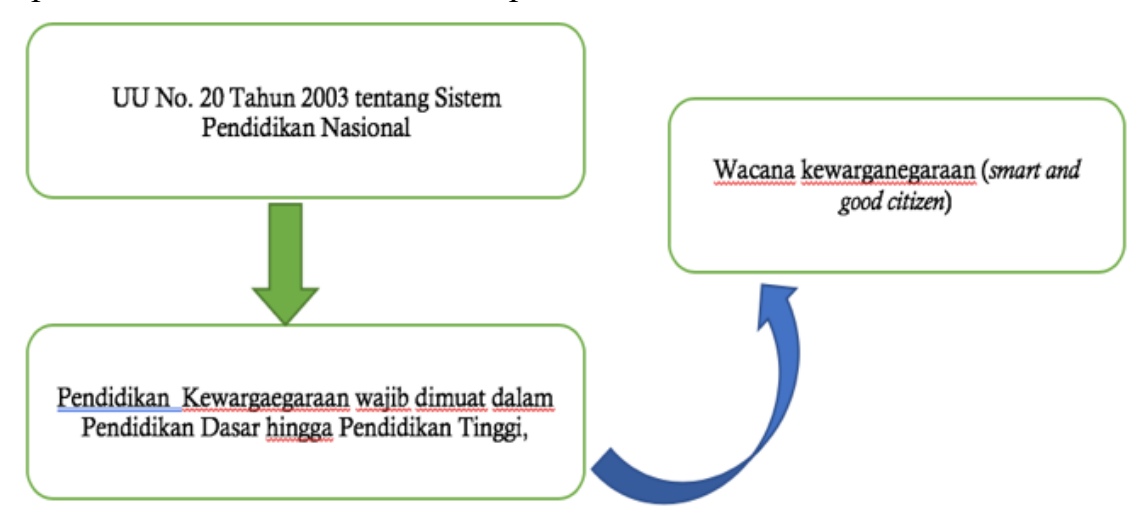

Gambar 2. Dasar HukumPendidikan Kewarganegaraan di Indonesia

Sumber: data diolah peneliti berdasarkan hasil kajian

Melalui hasil pembahasan ini peneliti menyapaikan implikasi hasil penelitian baik dari teoritis maupun penerapan sebagai berikut.

\section{Implikasi teoritis}

Hasil penelitian mengenai reorientasi Pendidikan Pancasila Dan Kewarganegaraan pada Sekolah Dasar dalam wacana kewarganegaraan smart and good citizen peneliti harapkan dapat menjadi sumbangsih pemikiran dalam perkembangan ilmu Pendidikan Pancasila Dan Kewarganegaraan secama umum, dan Pendidikan Pancasila Dan Kewarganegaraan di Sekolah dasar secara khusus.

\section{Implikas Penerapan}

Hasil penelitian mengenai reorientasi Pendidikan Pancasila Dan Kewarganegaraan pada Sekolah Dasar dalam wacana kewarganegaraan smart and good citizen peneliti harapkan dapat menjadi masukan atau parameter kepada pemangku kebijakan Pendidikan Pancasila Dan Kewarganegaraan

\section{KESIMPULAN}

Berdasarkan pembahasan yang telah dilakukan penulis dapat menyimpulkan reorientasi Pendidikan Pancasila Dan Kewarganegaraan pada membentuk karakter yang sesuai dengan sesuai dengan budaya bngsa Indonesia, diperlukan kegiatan diluar sekolah dan kelas (Adha \& Yanzi, 2012). Wacana smart and god citizen menjadi penegasan klaim bahwa Pendidikan Kewarganegaraan merupakan bagian dari pendidikan karakter (Winarno, 2012). Pendidikan Kewarganegaraan merupakan bagian luas dari pendidikan karakter (Winarno, 2012).

Secara umum, hasil kajian dapat digambarkan sebagai berikut:

\section{Sekolah Dasar dalam wacana kewarganegaraan smart and good citizen merupakan salah satu penegasasan klaim bahwa Pendidikan Pancasila dan Kewarganegaraan merpakan bagian luas dari Pendidikan Karakter.}

Wacana kewarganegaraan Smart and God Citizen merupakan term yang mengacu pada pembentukan warga negara yang cerdas, baik. Pemaknaan nya merupakan warga negara yang cerdas dan baik dalam berpartisipasi kenegaraan. Melalui kajian ini, peneliti memberikan rekomendasi terhadap peneliti selanjutnya yang ingin mengkaji issue yang serupa agar melakukan kajian yang meluas dan mendalam mengenai Pendidikan Pancasila dan Kewarganegaraan di Sekolah Dasar

\section{DAFTAR PUSTAKA}

Adawiah, R. (2016). Profeseonalitas guru dan pendidikan karakter (kajian emperis di SDN Kabupaten Balangan). Jurnal Pendidikan Kewarganegaraan, 6(11), 939-946.

Adha, M. M., \& Yanzi, H. (2012). Model pengembangan pembelajaran Pendidikan Kewarganegaraan berbasis multikultur 
dalam rangka menanamkan nilai-nilai HAM dan demokrasi. Jurnal Media Komunikasi FIS, 12(1), 1-16.

Afandi, R. (2011). Integrasi pendidikan karakter dalam pembelajaran ips di sekolah dasar. PEDAGOGIA Vol., 1(1), 85-98.

Ananda, A. (2012). Pendidikan kewarganegaraan dan pendidikan karakter bangsa. Jurnal Demokrasi, 11(1), 258-283.

Branson, M. S. (1999). Making the case for civic education: Where we stand at the end of the 20th century. CCE.

Cohen, T. R., Morse, L., \& Cleary, M. (2014). Moral character: What it is and what it does. In Research in Organizational Behavior (Vol. 34, hal. 43-61). Elsevier. https://doi.org/10.1016/j.riob.2014.08.003

De Coster, I., \& Sigalas, E. (2017). Citizenship Education at School in Europe, 2017. Eurydice Brief. ERIC.

Galih Puji Mulyoto, Nur Hidayah Hanifah, R. A. (2018). Pendidikan Pancasila dan Kewarganegaraan untuk MI/SD. Program Studi Pendidikan Guru Madrasah Ibtidaiah Fakultas Ilmu Tarbiah Dan Keguruan (FITK) Universitas Islam Negeri Maulana Malik Ibrahim Malang.

Gholtash, A., \& Yarmohammadian, M. H. (2011). A critical analysis of the progressive Citizenship Education approach in Iran's elementary school curriculum. Procedia - Social and Behavioral Sciences, 15, 76-79. https://doi.org/10.1016/j.sbspro.2011.03.05 4

Hardianto, P. D. (2014). Pentingnya pendidikan interreligiusitas di sekolah dasar. Jurnal Teologi, 03(01), 13-24.

Harmanto, Listyaningsih, R. W. (2018). Characteristics of competence and civic education materials curriculum in primary school in Indonesia. The 2nd International Joint Conference on Science and Technology (IJCST) 2017, 1.

Harmanto, Listyaningsih, \& Wijaya, R. (2018). Characteristics of competence and civic education materials curriculum in primary school in Indonesia. Journal of Physics: Conference Series, 953(1). https://doi.org/10.1088/1742-
$6596 / 953 / 1 / 012150$

Heater, D. (2002). World citizenship. Cosmopolitant thinking and its opponents. Continuumi.

Hidayah, Y., Retansari, L., \& Ulfah, N. (2018). Pendidikan karakter religius pada sekolah dasar: sebuah tinjuan awal. Jurnal Iqra': Kajian Ilmu Pendidikan, 3(2), 329-344.

Izzaty, R. E. (2008). Perkembangan peserta didik. UNY Press.

Kamaruddin, S. A. (2012). Character Education and Students Social Behavior. Journal of Education and Learning, 6, 223-230.

Lin, A. R. (2015). Citizenship education in American schools and its role in developing civic engagement: a review of the research. Educational Review, January. https://doi.org/10.1080/00131911.2013.813 440

Mahmud. (2011). Metode penelitian pendidikan. Pustaka Setia.

Character and Citizenship Education Syllabus Primary, (2014).

Nuci, L., Narvaez, D., \& Krettenauer, T. (Ed.). (2014). Handbook of moral and character education (2 ed.). Routledge.

Pasoula, E. (2001). The development of moral, social and citizenship education in the context of the ethos and the curriculum of Greek primary schools: five case studies . Eirini Pasoula Thesis submitted for the degree of Doctor of Philosophy in the University of London, (Nomor May). University of London,.

Pineda-Alfonso, J. A. (2016). Citizenship education as an integrative purpose of the curriculum: potentials and difficulties (Nomor April). https://doi.org/10.13140/RG.2.1.3469.2968

Proctor, C. L. (2016). The Importance of Good Character. In Chapter 2: The Importance of Good Character (Nomor April 2015). https://doi.org/10.1007/978-94-007-6398-2

Pykett, J., Saward, M., \& Schaefer, A. (2010). Framing the good citizen. British Journal of Politics and International Relations, 12(4), 523-538. https://doi.org/10.1111/j.1467856X.2010.00424.X

Sholeh, A. R. (2005). Pendidikan Agama dan 
Pengembangn untuk Bangsa. PT. Raja Grafindo Persada.

Sudrajat, A. (2011). Mengapa pendidikan karakter? Jurnal Pendidikan Karakter, 1(1), 47-58.

Suyato, Murdiono, M., Mulyono, B., \& Arpannudin, I. (2016). Upaya pembentukan warga negara yang baik dan tantangan yang dihadapi oleh para guru PKn peserta SM3T 2015. Jurnal Civics: Media Kajian Kewarganegaraan, 13(2), 137-150. https://doi.org/10.21831/civics.v13i2.12737

Winarno. (2012). Karakter warga negara yang baik dan cerdas. PKn Progresif, 7(1), 5462.

Winataputra, U. S. (2016). Posisi akademik pendidikan kewarganegaraan (PKn) dan muatan/ mata pelajaran PPKn dalam konteks sistem pendidikan nasional. Jurnal Moral Kemasyarakatan, 1(1), 15-36. 